\title{
Surgical Training and Standardised Management Guidelines Improved the 30-Day Complication Rate After Abdominoplasty for Massive Weight Loss
}

\author{
E. Swedenhammar ${ }^{1,2} \cdot$ B. Stark ${ }^{1,3}$ - A. Hedén Hållstrand ${ }^{4}$ M. Ehrström ${ }^{1,3}$ • \\ J. Gahm ${ }^{1,3}$
}

Published online: 28 November 2017

(C) The Author(s) 2017. This article is an open access publication

\begin{abstract}
Background An increasing number of patients need reconstructive surgery after massive weight loss. The hypothesis was that surgical experience together with standardised management guidelines significantly decreases early complication rates after abdominoplasty for massive weight loss. The primary aim was to assess the 30-day complication rate after abdominoplasty following increased surgical training and experience. The secondary aim was to assess whether optimised management guidelines have an impact on the complication rate and patient safety.

Methods The outcome of 69 consecutive abdominoplasties operated by surgeons in 2011 (Group A) and 70 consecutive patients operated by plastic surgeons in 2010-2012 (Group B) was compared. Another Group of 70 consecutive patients operated by surgeons in 2013-2014 (Group C) was assessed since standardised guidelines for pre- and post-operative treatments and refinement of surgical technique had been introduced. The same surgeons participated in operations of Groups A and C. $\chi^{2}$-test and Fisher's exact test were applied to dichotomous data. Logistic regression test and ANOVA were used.

Results Group C had more comorbidities and was significantly older. 48 patients in Group A (70\%), 31 in Group B (44\%) and 13 patients in Group C (19\%) had early complications. A significantly decreased rate of complications occurred with improved guidelines and surgical training and experience. (A vs. C $p<0.001$ and A vs. B $p=0.008$ ). Conclusions Our results indicate that the rate of early complications after abdominoplasty for massive weight loss can be significantly reduced with improved surgical experience and standardised management guidelines.

Registered at Clinical Trial.gov (ID: NCT02679391).
\end{abstract}

M. Ehrström and J. Gahm have contributed equally to this work.

E. Swedenhammar

ebba.swedenhammar@ki.se

B. Stark

birgit.stark@ki.se

A. Hedén Hållstrand

amanda.hedenhallstrand@capio.se

M. Ehrström

marcus.ehrstrom@sll.se

J. Gahm

jessica.gahm@sll.se
1 Department of Molecular Medicine and Surgery, Karolinska Institute, Karolinska vägen, 17176 Stockholm, Sweden

2 Department of Surgery, Capio S:t Görans Hospital, Stockholm, Sweden

3 Department of Plastic and Reconstructive Surgery, Karolinska University Hospital, Solna, Sweden

4 Capio Dalen Geriatric Hospital, Stockholm, Sweden 


\section{Introduction}

Bariatric surgery is possibly the most effective way to obtain sustainable weight loss when BMI exceeds $40[1,2]$. Massive weight loss leaves the patient with excessive soft tissue at various locations including the abdomen [3]. About $75-82 \%$ of post-bariatric surgical patients wish to undergo body contouring surgery in Sweden, and some of these operations are performed in general surgical units [4-7].

Body contouring surgery is associated with a high risk for surgical complications [8]. A report from the Swedish government states the importance of high volume of surgical procedure per surgeon and centralisation to fewer hospitals to decrease the level of complications in highly specialised care [9]. There is no clear data if this also applies to abdominoplasty.

The hypothesis of this study was that surgical training and experience together with standardised management guidelines significantly decrease early complication rates after abdominoplasty for massive weight loss. The primary aim of this study was to assess the 30-day complication rate after abdominoplasty for massive weight loss following increased surgical training and experience. The secondary aim was to assess whether optimised management guidelines have an impact on the complication rate and patient safety. The aesthetic outcome was not investigated in this study.

This study was approved by the Regional Ethics Review Board in Stockholm (D. nr. 2012/1997-31/4, 2015/201732). Registered at Clinical Trial.gov (ID: NCT02679391).

\section{Materials and methods}

\section{Patients}

This was a retrospective cohort study. All patients included in the study were admitted for surgery based on the Swedish national criteria for massive weight loss [10] and first assessed at the Department of Reconstructive Plastic Surgery, Karolinska University Hospital, Stockholm,
Sweden (Table 1), the allocation of patients only depending of the waiting list at Karolinska Hospital. The cohorts of patients were not biased regarding age, BMI or other criteria. The timeline for those assessed is shown in Fig. 1. Patients were found by searching medical records for the national operation codes for abdominoplasty (QBJ00QBJ99). The patients were operated either at the Department of Reconstructive Plastic Surgery, Karolinska University Hospital or at the Department of General Surgery, Capio S:t Görans Hospital, Stockholm. At S:t Görans Hospital each procedure was performed by any two of four specialists in general surgery. The four general surgeons at St Görans Hospital had a special interest to start performing abdominoplasties. During the first (less than 10) operations in Group A, a plastic surgeon supervised and educated the general surgeons in a systemic manner.

At the Department of Reconstructive Plastic Surgery, each procedure was performed by any of 15 specialists in plastic surgery although not always with specific training in body contouring surgery. Records were retrieved from the first 69 consecutive patients operated by the general surgeons at Capio S:t Görans Hospital, Stockholm, Sweden (Group A) from 13th of May to 19th of December 2011. Records from 70 consecutive patients operated from 14th of January 2010 to 7th of December 2012 by plastic

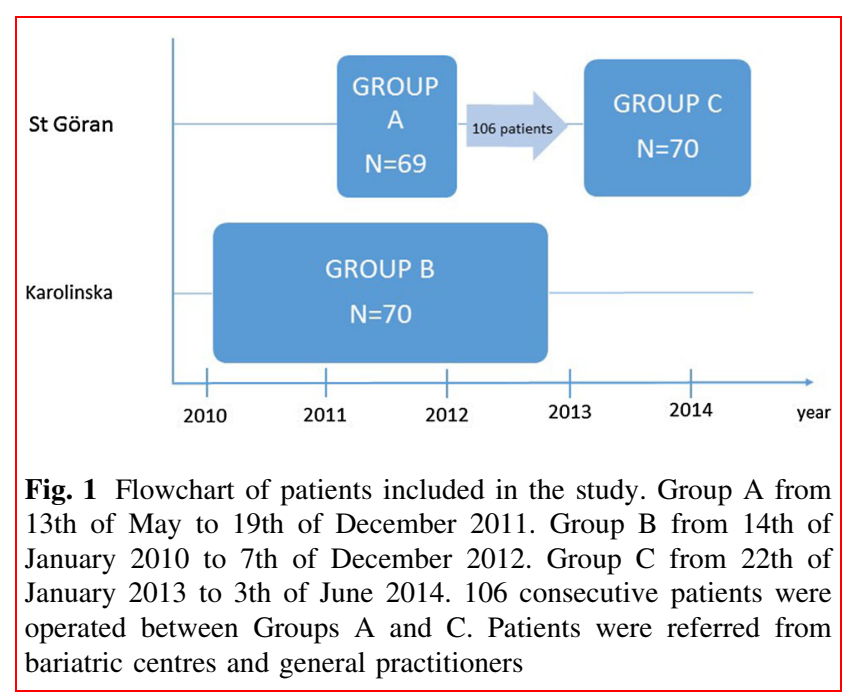

Table 1 Patients included and excluded in accordance with national guidelines for abdominoplasty after massive weight loss ${ }^{10}$

\begin{tabular}{ll}
\hline Indications & Contraindications \\
\hline Abdominal skin ptosis $\geq 3 \mathrm{~cm}$ & Weight instability \\
Weight stability $\geq 6$ months & Smoking \\
Smoke-free $\geq 6$ weeks prior to surgery & BMI $>35$ \\
BMI $\leq 28$ or a significant weight reduction equivalent to $80 \%$ of excess weight & Psychological imbalance or non-treated psychiatric disease \\
& Advanced cardiovascular disease \\
\hline
\end{tabular}


Table 2 Guidelines for patients in Group C

Guidelines

Medication

Paracetamol $665 \mathrm{mg} \times 3,1$ week

Oxycodone slow release $10 \mathrm{mg} \times 2$, 1 week

Oxycodone $5 \mathrm{mg}$ when needed

Tranexamic acid $1 \mathrm{~g} \times 3$ for 1 day, but not if there is a drop in Haemoglobin over $30 \mathrm{~g} / \mathrm{L}$

Antibiotics: isoxazolpenicillin $2 \mathrm{~g}$ pre-operative or clindamycin $600 \mathrm{mg}$

Low molecular-weight heparin, 2500-5000IE $\times 1,10$ days post-operative

Mobilization

Early mobilisation, as soon as possible after surgery

Firm girdle 4 weeks

Underwear girdle for 3 months

Controls

Haemoglobin: pre-operative and every $8 \mathrm{~h}$ post-operatively Day 1 and thereafter once a day

MEWS (Modified Early Warning Score): once every 4 h Day 1 post-operatively

surgeons at the Department of Plastic and Reconstructive Surgery, Karolinska University Hospital, Stockholm, Sweden (Group B) were assessed. Due to waiting time and operation queues at Karolinska University Hospital, the period for Group B was considerably lengthier. All information was collected by the authors ES and $\mathrm{AH}$.

Two years after, the general surgeons started to perform abdominoplasties at St Görans Hospital records from another 70 consecutive patients were evaluated, between 22th of January 2013 to 3rd of June 2014 (Group C). Between Group A and $C$, the pre-, peri- and post-operative care guidelines had been standardised and implemented (Table 2), thus the starting date for Group C. All patients in Group $\mathrm{C}$ were operated by the same four general surgeons, and the outcome was compared with those of Groups B and A. One hundred and six consecutive patients (not investigated in this study) were operated by the same group of general surgeons between the end of Group A and beginning of Group C. Patient demographics are shown in Table 3. A period of 4-6 weeks of non-smoking was recommended before surgery. The unknown number of smokers could have been higher, and it was, therefore, difficult to comment on the impact of smoking on the results. Follow-up assessments in all groups were performed after one week by a nurse, and after three months by a senior surgeon.

\section{Surgery}

A team of 2 general surgeons in Groups $\mathrm{A}$ and $\mathrm{C}$ and 2 plastic surgeons in Group B performed each operation (Table 4). The same group of surgeons participated in surgery on Groups A and C. Some plastic surgeons performed liposuction before the abdominoplasty in Group B. When appropriate a panniculectomy was performed $[11,12]$. An abdominal rectus diastasis (ARD) wider than
$3 \mathrm{~cm}$ was repaired with a double row of absorbable, selfretaining barbed suture, PDO 2/0. When detected intraoperatively, midline and incisional hernias were repaired with double row sutures. Post-operative drains were used in all patients in Groups A and B, but varied in Group C depending on the surgeon's preference.

\section{Complications}

Early 30-day complications were defined as minor or major. Wound infection, seroma and small wound dehiscence were defined as minor whereas post-operative bleeding, tissue necrosis, thromboembolism, revision surgery and systemic events requiring intensive care treatment were considered major complications. For better comparison, a Clavien Dindo (C-D) table was created [13]. Wound infection (C-D class II) was defined by the administration of oral or intravenous antibiotics secondary to local or systemic signs of infection. Seroma (C-D class I) was only reported when it was described in the notes either as a swollen abdomen 1 week after surgery or when aspirated (C-D class IIIa).

\section{Standardised management guidelines in Group C}

Guidelines applied to Group $\mathrm{C}$ included the administration of tranexamic acid, intravenous antibiotics, and focused on optimal perioperative and post-operative care (Table 2). By the time Group $\mathrm{C}$ was investigated, all patients had received the same perioperative and post-operative care, and a more well-defined surgical technique used, including meticulous haemostasis of the perforator vessels and less extensive dissection of the upper part of the abdominal wall. Post-operative care was standardised in Group C (Table 2). There were no equivalent guidelines in Group A or B. 
Table 3 Descriptive statistics for patient Groups A, B and C

\begin{tabular}{lllll}
\hline & $\mathrm{A}(n=69)$ & $\mathrm{B}(n=70)$ & $\mathrm{C}(n=70)$ & $p$ value overall test \\
\hline Female, $n(\%)$ & $66(95.7 \%)$ & $60(85.7 \%)$ & $63(90 \%)$ & 0.136 \\
Age, mean (sd) & $41.4(9.5)$ & $38.6(11.37)$ & $46.8(10.07)^{* *}$ & $<0.001$ \\
BMI before surgery, mean (sd) & $26(1.91)$ & $26.3(2.16)$ & $26^{\mathrm{a}}(1.69)$ & 0.596 \\
Skin ptosis (cm), mean (sd) & $4.4(1.51)$ & $4.4^{\mathrm{b}}(1.3)$ & $4.2(1.09)$ & 0.473 \\
Weight loss in BMI units, mean (sd) & $17.8^{\mathrm{c}}(5.12)$ & $17.4^{\mathrm{c}}(4.8)$ & $16.3^{\mathrm{c}}(5.11)$ & 0.236 \\
ASA 1, $n(\%)$ & $45(65.2 \%)$ & $46(65.7 \%)$ & $32(45.7 \%)^{*}$ & 0.0332 \\
ASA 2, $n(\%)$ & $24(34.8 \%)$ & $22(31.4 \%)$ & $36(51.4 \%)^{*}$ & $2(2.9 \%)$ \\
ASA 3, $n(\%)$ & $0(0 \%)$ & $2(2.9 \%)$ & & $1(1.4 \%)$ \\
Diabetes & & & $7(10 \%)$ \\
Type I, $n(\%)$ & $1(1.4 \%)$ & $0(0 \%)$ & $26(37.1 \%)$ & 0.368 \\
Type II, $n(\%)$ & $2(2.9 \%)$ & $1(1.4 \%)$ & $15(21.4 \%)$ & 0.040 \\
Former smokers & $10(14.5 \%)$ & & 0.01 \\
\hline
\end{tabular}

$p$ values for overall tests are presented. If $p<0.05$, pairwise comparisons for A versus B and A versus C are calculated and presented as $* p<0.05, * * p<0.01$ and ${ }^{* * *} p<0.001$

Smokers are presented as former smokers, but the charts did not always clearly state (in Group C) whether the habit had ceased or not

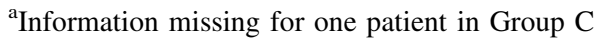

${ }^{\mathrm{b}}$ Information missing for nine patients in Group B

${ }^{\mathrm{c}}$ Information missing for three patients in Group A, two patients in Group B and three patients in Group C

Table 4 Operation data for patient Groups A, B and C presented as number and proportion (\%) or median (Md)

\begin{tabular}{llllr}
\hline & A $(n=69)$ & B $(n=70)$ & C $(n=70)$ & $p$ value overall test \\
\hline Abdominoplasty & $69(100 \%)$ & $67(96 \%)$ & $70(100 \%)$ & 0.108 \\
Hernia repair & $1(1 \%)$ & $7(10 \%)$ & $5(7 \%)$ & 0.088 \\
Plication of ARD & $3(4 \%)$ & $25(36 \%)^{* * *}$ & $5(7 \%)$ & $<0.001$ \\
T-incision & $2(3 \%)$ & $4(6 \%)$ & $1(1 \%)$ & 0.411 \\
Resected tissue (g), Md (95\% CI) & $1685(1538.6-1943.6)$ & $1370.5^{\mathrm{a}}(1205.2-1554.9)$ & $1524(1338.6-1718.5)$ & 0.053 \\
Liposuction & $0(0 \%)$ & $10(14 \%)^{* *}$ & $0(0 \%)$ & $<0.001$ \\
Drain-bilateral & $69(100 \%)$ & $70(100 \%)$ & $24(34 \%)^{* * *}$ & $<0.001$
\end{tabular}

$p$ values from overall tests are presented. If $p<0.05$, pairwise comparisons for A versus B and A versus C are calculated and presented as $* p<0.05, * * p<0.01$ or $* * * p<0.001$

${ }^{\mathrm{a}}$ Information missing for four patients in Group A and two patients in Group B

\section{Statistics}

$\chi^{2}$-test and Fisher's exact test were applied to dichotomous data. The demographic data of the patients were expressed as median and standard deviations. Logistic regression test and ANOVA were used. Since there were three groups, ANOVA was used to check if overall differences between the groups were significant, and if so each variable was tested $\mathrm{A}$ versus $\mathrm{B}$ and $\mathrm{A}$ versus $\mathrm{C}$. To avoid the risk of random errors, $\mathrm{B}$ versus $\mathrm{C}$ was not calculated. There was no randomisation of patients in the three cohorts, and any difference calculated could have been the result of patients systematically differing in one or more variables. To avoid this bias, a logistic regression analysis adjusting for age, BMI and ASA-class were completed. Since many variables had a low prevalence, separate models were not estimated for each complication. The model used estimated the occurrence of (1) at least one minor complication, (2) at least one major complication and (3) no complication. The statistics was calculated by R Software for Mac version 3.2.2.

\section{Results}

\section{Patients}

Prior to surgery the 3 groups were similar in terms of mean BMI and mean skin ptosis. Patients in Group $\mathrm{C}$ were significantly older with more comorbidity than those in 
Groups A and B. Group C had a significantly higher prevalence of ASA II $(p=0.027$, Group A vs. C) (Table 3).

\section{Surgery and medication}

More extensive surgery took place in Group B (Table 4). There was a significant difference in pre-, intra- and postoperative medications between all three groups (Table 5). One dose of intravenous or oral antibiotics was administrated, isoxazolylpencillin or, if allergic, a lincosamide, at least $30 \mathrm{~min}$ prior to surgery. Eleven patients (16\%) received one dose of intravenous antibiotics in Group A, compared to 27 (39\%) in Group B (Group A vs. B, $p=0.004)$. Sixty-six patients $(94 \%)$ in Group $\mathrm{C}$ received one dose of intravenous antibiotics (Group A vs. C, $p<0.001)$.

No patient was given tranexamic acid in Group A, whereas 9 patients (13\%) received tranexamic acid in Group B (Group A vs. B, $p=0.003$ ), and 65 patients (93\%) in Group C (Group A vs. C, $p<0.001$ ). Low molecular weight heparin 10 days post-operatively (Frag$\min ^{\circledR} 5000 \mathrm{IE}$ or Klexane $\left.{ }^{\circledR} 100 \mathrm{mg} / \mathrm{ml}, 0.4 \mathrm{ml}\right)$ was prescribed to all the patients in Group A (100\%), to 37 patients $(53 \%)$ in Group B (the length of treatment varying from 3 to 12 days) and to 63 of the patients (90\%) in Group C.

\section{Complications}

Complications are shown in Tables 6 and 7.48 patients in Group A (70\%), 31 in Group B (44\%) and 13 patients in Group C (19\%) had early complications. The difference between Groups $\mathrm{A}$ and $\mathrm{C}$ and between Groups $\mathrm{A}$ and $\mathrm{B}$ were statistically significant $(p<0.001$ and $p=0.008$, respectively).

\section{Minor complications}

Wound infection (Clavien-Dindo classification II) was most common in Group A, 32 patients (49\%) compared to 19 patients in Group B $(27 \%, p=0.014$ compared to Group A), and 7 patients in Group C $(10 \%, p<0.001$ compared to group A). A seroma (C-D class I) occurred in
8 patients in Group A (12\%), in 5 patients in Group B (7\%) and in 6 patients in Group C (9\%).

\section{Major complications}

Bleeding (C-D class I) was significantly higher in Group A (22 patients, 32\%) than in Group B (7 patients, $p=0.003$ ) and Group C (A vs. C, $p<0.001$ ). Significantly, more patients in Group A (12 patients, 17\%) versus 3 in Group B $(4 \%, p=0.015)$ required post-operative blood transfusion (C-D class II). Two of the patients in Group A required intensive care for hypovolemic shock, and one patient needed intensive care due to over-dosage of opioids (C-D IVa). No thromboembolic events were seen in any of the three groups.

Univariate analysis showed an overall statistical difference between the cohorts for six of the variables. The results, shown in Table 8 , showed a difference remaining between the cohorts when adjusted for the demographic variables. The odds of a minor or major complication occurring were higher in Group A compared to Groups B and $\mathrm{C}$, respectively.

\section{Discussion}

Facing a growing population of massive weight loss patients and the high-reported incidence of early complications after body contouring surgery [8, 14], the aim was to assess if increased surgical experience and training in performing abdominoplasties combined with standardised management guidelines decreased 30-day complication rates after abdominoplasty. The frequency of complications in Group A was unacceptable and the reason that the general surgeons developed new management guidelines. The overall complication rates in Group B were in line with previously reported data [10, 14-17]. Previously reported studies indicate overall complication rates as high as $55.5 \%$. Age, smoking, male gender, multiple procedures and body mass index are independent risk factors that increase the risk for complications [14-17]. In a recent retrospective study by Botero et al., similar results were seen when assessing 153 patient with body contouring

Table 5 Recommendations for prophylaxis treatment in patient Groups A, B and C presented as numbers and proportion (\%)

\begin{tabular}{lcccc}
\hline & $\mathrm{A}(n=69)$ & $\mathrm{B}(n=70)$ & $\mathrm{C}(n=70)$ & $p$ value overall test \\
\hline Antibiotics & $11(16 \%)$ & $27(39 \%)^{* * *}$ & $66(94 \%)^{* * *}$ & $<0.001$ \\
Tranexamic acid & $0(0 \%)$ & $9(13 \%)^{* *}$ & $65(93 \%)^{* * *}$ & $<0.001$ \\
\hline
\end{tabular}

$p$ values from overall tests are presented. If $p<0.05$, pairwise comparisons for A versus B and A versus $\mathrm{C}$ are calculated and presented as $* p<0.05, * * p<0.01$ or $* * * p<0.001$ 
Table 6 Complication data for patient Groups A, B and C presented as numbers and proportion (\%)

\begin{tabular}{|c|c|c|c|c|}
\hline & $\mathrm{A}(n=69)$ & $\mathrm{B}(n=70)$ & $\mathrm{C}(n=70)$ & $p$ value overall test \\
\hline \multicolumn{5}{|l|}{ Minor complication } \\
\hline Wound infection & $32(49 \%)^{\mathrm{a}}$ & $19(27 \%)^{*}$ & $7(10 \%)^{* * *}$ & $<0.001$ \\
\hline Seroma & $8(12 \%)$ & $5(7 \%)$ & $6(9 \%)$ & 0.648 \\
\hline Wound dehiscence & $5(7 \%)$ & $3(4 \%)$ & $1(1 \%)$ & 0.202 \\
\hline \multicolumn{5}{|l|}{ Major complication } \\
\hline Bleeding & $22(32 \%)$ & $7(10 \%)^{* *}$ & $5(7 \%)^{* * *}$ & $<0.001$ \\
\hline Transfusion & $12(17 \%)$ & $3(4 \%)^{*}$ & $0(0 \%)^{* * *}$ & $<0.001$ \\
\hline Tissue necrosis & $2(3 \%)$ & $2(3 \%)$ & $0(0 \%)$ & 0.474 \\
\hline Thromboembolic event & $0(0 \%)$ & $0(0 \%)$ & $0(0 \%)$ & $>0.999$ \\
\hline Reoperation & $3(4 \%)$ & $1(1 \%)^{b}$ & $0(0 \%)$ & 0.130 \\
\hline Intensive care unit stay & $3(4 \%)$ & $0(0 \%)$ & $0(0 \%)$ & 0.035 \\
\hline Patients with complications & $48(70 \%)^{\mathrm{a}}$ & $31(44 \%)^{\mathrm{c}} * *$ & $13(19 \%) * * *$ & $<0.001$ \\
\hline
\end{tabular}

$p$ values from overall tests are presented. If $p<0.05$, pairwise comparisons for A versus B and A versus C are calculated and presented as $* p<0.05, * * p<0.01$ or $* * * p<0.001$

${ }^{\mathrm{a}}$ Information missing for four patients in Group A

${ }^{\mathrm{b}}$ Information missing for one patient in Group B

${ }^{\mathrm{c}}$ Information missing for four patients in Group A and one patient in Group B

Table 7 Complications classified in accordance with Clavien-Dindo

\begin{tabular}{lccl}
\hline & $\mathrm{A}(n=69)$ & $\mathrm{B}(n=70)$ & $\mathrm{C}(n=70)$ \\
\hline I & $7(10 \%)$ & $4(6 \%)$ & $5(7 \%)$ \\
II & $34(49 \%)$ & $19(27 \%)$ & $7(10 \%)$ \\
IIIa & $0(0 \%)$ & $4(6 \%)$ & $0(0 \%)$ \\
IIIb & $3(4 \%)$ & $1(1 \%)^{\mathrm{a}}$ & $0(0 \%)$ \\
IV & $3(4 \%)$ & $0(0 \%)$ & $0(0 \%)$ \\
V & $0(0 \%)$ & $0(0 \%)$ & $0(0 \%)$ \\
\hline
\end{tabular}

The highest-ranking complication is registered for each patient. Groups A, B and C presented as numbers and proportion (\%)

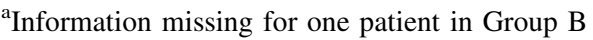

surgery [17], with the larger part of complications defined as minor (C-D I-IIIa). In $i$, however, these were significantly higher despite more extensive surgery in Group B with comparable patient demographics. This possibly reflects a difference in plastic surgery training, i.e. experience of performing abdominoplasty, between the surgeons performing the procedures in Group A (General surgeons) and those in Group B (plastic surgeons) as discussed by Mioton et al. [18]. The four general surgeons had very small experience of abdominoplasties prior to Group $\mathrm{A}$ and improvement in complication rates between Groups $A$ and $C$ could partially be explained by improved surgical experience.

Between Groups A and C, improved pre-, intra- and post-operative management routines and checklists had been introduced (Tables 2, 5). Despite more comorbidity and higher ASA grades in Group C compared to Group A, fewer major complications were noted, which the regression analysis confirmed. One must take into account the team surrounding the patient at the general surgical ward and in the OR got more experienced and perhaps added to

Table 8 OR (odds ratio) and 95\% confidence interval estimated from logistic regression for outcome $\geq 1$ minor complication, $\geq 1$ major complication and no complication

\begin{tabular}{|c|c|c|c|}
\hline Group & $\begin{array}{l}\geq 1 \text { Minor complication }(n=204) \text { Adjusted }^{\mathrm{a}} \\
\text { OR }(95 \% \mathrm{CI})\end{array}$ & $\begin{array}{l}\geq 1 \text { Major complication }(n=207) \text { Adjusted }^{\mathrm{a}} \\
\text { OR }(95 \% \mathrm{CI})\end{array}$ & $\begin{array}{l}\text { No complication }(n=203) \text { Adjusted }^{\text {a }} \\
\text { OR }(95 \% \text { CI })\end{array}$ \\
\hline A & Ref & Ref & Ref \\
\hline B & $0.29(0.132-0.601)$ & $0.46(0.209-0.993)$ & $3.18(1.538-6.769)$ \\
\hline $\mathrm{C}$ & $0.17(0.069-0.376)$ & $0.19(0.067-0.467)$ & $9.04(4.059-21.368)$ \\
\hline
\end{tabular}

ORs are adjusted for age, BMI and ASA-class at the time of surgery

${ }^{\text {a }}$ The numbers do not add up to 209 patients due to information missing in all three groups, as shown in Table 6 
the results in Group C, but the management guidelines also helped. The improved surgical experience/technique of performing abdominoplasties appears to have had a substantial effect, significantly decreasing the overall complication rate. This is in line with international trends and experience in both highly specialised care and more routine surgery such as hernia repair, where high-volume surgery performed by fewer surgeons significantly increase overall survival and patient safety, and decrease complication rates [19].

Pre-operative antibiotic prophylaxis, as one dose preoperatively, seems to lower the risk for wound infection in our study. Data on the usefulness of antibiotics are conflicting and consensus is lacking. The prophylactic use of antibiotics is advisable according to the Swedish Council on Health Technology Assessment, but evidence in the case of abdominoplasty is low [20]. Data providing convincing evidence on the effect of tranexamic acid on blood loss during reconstructive plastic and breast surgery are sparse [21-23]. The usage of both tranexamic acid and LMWH can seem contradictive, and the scientific evidence for this approach are sparse nevertheless, it is not unheard of [24].

The repair of the rectus diastasis differed between the groups. A diastasis wider than 3 centimetres is considered pathological [25] and plastic surgeons by tradition repair rectus diastasis perhaps in contrast to general surgeons. The use of drains was largely omitted in Group C in contrast to common routine. In a retrospective study from Rodby et al., it was shown that abdominoplasty with lesser undermining above the umbilicus, liposuction, and no postoperative drain resulted in fewer infections, and the seroma rate was in the lower range of the spectrum [26]. Highquality evidence-based reports with comparable groups and operative techniques are insufficient. The present study revealed that patients in all 3 groups had seroma and our data are in concordance with other reports with prevalence rates of $5-30 \%$ [27-30].

\section{Strengths of the study}

Patients were operated consecutively in all three Groups. Group C was assessed when all management guideline improvements had been implemented. Statistical calculations were applied systematically and potential bias in interpretation was investigated with appropriate regression analysis.

\section{Weaknesses of the study}

This is a retrospective cohort study. The lack of standardised criteria for some of the complications introduced a degree of subjectivity of assessment by the investigating surgeon at follow-up. The present study gives an overview of retrospective data and general conclusions can thus be questioned. A general registry for complications after abdominoplasty for massive weight loss does not exist, but could be a part of the existing registry for bariatric surgery in the future. The systematic registration of such data would certainly help to provide more statistically conclusive evidence.

\section{Conclusions}

This study provides good statistical evidence for an observed trend in terms of improved surgical experience and training in performing abdominoplasties and standardised management guidelines leading to significant reductions in surgical complication rates and increased safety for the patient. Aesthetic outcome and patient satisfaction were not addressed in this study, but should be considered in future studies.

Acknowledgements The authors thank Anna-Maria Kling for her help with the statistical analyses, and Dr. Marcus Holmberg and Dr. Leonid Margolin for defining management guidelines at S:t Görans Hospital.

Funding This work received funding from the National Cooperation for Medical Education and Research (ALF).

\section{Compliance with ethical standards}

Conflict of interest All the authors declare that they have no conflicts of interest.

Open Access This article is distributed under the terms of the Creative Commons Attribution 4.0 International License (http://crea tivecommons.org/licenses/by/4.0/), which permits unrestricted use, distribution, and reproduction in any medium, provided you give appropriate credit to the original author(s) and the source, provide a link to the Creative Commons license, and indicate if changes were made.

\section{References}

1. Sjöström L, Lindroos A-K, Peltonen M et al (2004) Lifestyle, diabetes, and cardiovascular risk factors 10 years after bariatric surgery. N Engl J Med 351(26):2683-2693

2. Neff KJ, Olbers T, Le Roux CW (2013) Bariatric surgery: the challenges with candidate selection, individualizing treatment and clinical outcomes. BMC Med 11(8):1-17 
3. Shermak M, Bluebond-Langner R, Chang D (2008) Maintaince of weight loss after body contouring surgery for massive weight loss. Plast Reconstr Surg 121:2114-2119

4. Biörserud C, Olbers T, Fagevik Olsén M (2011) Patients' experience of surplus skin after laparoscopic gastric bypass. Obes Surg 21:273-277

5. Kitzinger H, Abayev S, Pittermann A et al (2012) The prevalence of body contouring surgery after gastric bypass surgery. Obes Surg 22:8-12

6. Staalesen T, Fagevik Olsén M, Elander A (2013) Experience of excess skin and desire for body contouring surgery in post-bariatric patients. Obes Surg J 23:1632-1644

7. Nationella Medicinska Indikationer-Bukplastik och liknande operationer; Rapport från expertgruppen för plastikkirurgi. Sveriges Kommuner och Landsting, 2008

8. Report from Regional Health Technology Health Assessment Centre (2009) Abdominal plastic surgery after massive weight reduction, vol 24. https://www2.sahlgrenska.se/upload/SU/HTAcentrum/HTA-rapport\%20Bukplastik\%20ink1\%20bilagor\%20200912-21\%20publicerad.pdf

9. Utredningen om högspecialiserad vård (SOU 2014:11) (2015) Koncentration av högspecialiserad vård. Arbetsmaterial. Socialdepartementet, Stockholm. Concentration of highly specialized health care. Ministry of Health and Social Affairs. http:// www.sou.gov.se/hogspecialiseradvard/. Accessed 20 Feb 2015

10. Riktlinjer för korrigerande plastikkirurgi efter viktnedgång. Region Skåne. Guidelines for Reconstructive Plastic Surgery after massive weight Loss. Region of Scania. https://www.skane. se/Public/SUS_extern/Verksamheter/Plastikkirurgiska_kliniken/ Dokument/Nationella\%20med\%20indikationer\%20bukplastik.pdf

11. Matarasso A, Moore Matarasso D, James Matarasso E (2014) Abdominoplasty: classic principles and technique. Clin Plast Surg 41(4):655-672

12. Colwell A (2010) Current concepts in post-bariatric body contouring. Obes Surg 20:1178-1182

13. Dindo D, Demartines N, Clavien P-A (2004) Classification of surgical complications. A new proposal with evaluation in a cohort of 6336 patients and a result of a survey. Ann Surg 240(2):205-213

14. Neaman K, Hansen J (2007) Analysis of complications from abdominoplasty: a review of 206 cases at a university hospital. Ann Plast Surg 58:292-298

15. Neaman K, Armstrong S, Baca M et al (2013) outcome of traditional cosmetic abdominoplasty in a community setting: a retrospective analysis of 1008 patients. Plast Reconstr Surg $131: 403 \mathrm{e}-410 \mathrm{e}$

16. Winocour J, Gupta V, Ramirez R et al (2015) Abdominoplasty: risk factors, complication rates, and safety of combined procedures. Plast Reconstr Surg 136:597e-606e
17. Botero G, Wenninger G, Loaiza F (2017) Complications after body contouring surgery in postbariatric patients. Ann Plast Surg 79:293-297

18. Mioton L, Buck D II, Gart M et al (2013) A multivariate regression analysis of panniculectomy outcomes: does plastic surgery training matter? Plast Reconstr Surg 131:604e-612e

19. Malik A, Bell C, Stukel T et al (2016) Recurrence of inguinal hernias repaired in a large hernia surgical specialty hospital and general hospitals in Ontario, Canada. Can J Surg 59:19-25

20. Swedish Council on Health Technology Assessment. AntibioticsThe correct prophylaxis prior to surgery can lower the risk for infections and reduce the resistance. http://www.sbu.se/globa lassets/publikationer/content0/1/antibiotikaprofylax_sammanfattning. pdf

21. Hogan C, Golightly L, Phong S et al (2016) Perioperative blood loss in total hip and knee arthroplasty: outcomes associated with intravenous tranexamic acid use in an academic medical center. SAGE open Med 4:1-6

22. Ker K, Edwards P, Perel P et al (2012) Effect of tranexamic acid on surgical bleeding: systematic review and cumulative metaanalysis. BMJ 344:e3054. https://doi.org/10.1136/bmj.e3054

23. Venturi M, Davison S, Caprini J (2009) Prevention of venous thromboembolism in the plastic surgery patient: current guidelines and recommendations. Aesthet Surg J 29(5):421-428

24. Gilette B, DeSimone L, Trousdale R et al (2013) Low risk of thromboembolic complications with tranexamic acid after primary total hip and knee arthroplasty. Clin Orthop Relat Res 471:150-154

25. Emanuelsson P, Gunnarsson U, Dahlstrand U et al (2016) Operative correction of abdominal rectus diastasis (ARD) reduces pain and improves abdominal wall muscle strength: a randomized, prospective trial comparing retromuscular mesh repair to double-row, self-retaining sutures. Surgery 160(5):1367-1375

26. Rodby K, Stepniak J, Eisenhut N et al (2011) Abdominoplasty with suction undermining and plication of the superficial fascia without drains: a report of 113 consecutive patients. Plast Reconstr Surg 128(4):973-981

27. Pierpont Y, Phoung Dinh T, Emerick Salas R et al (2014) Obesity and surgical wound healing: a current review. ISRN Obes 1:1-13

28. Greco J, Castaldo E, Nanney L et al (2008) The effect of weight loss surgery and body mass index on wound complications after abdominal contouring operations. Ann Plast Surg 3:235-242

29. Shermak M, Rotellini-Coltvet L, Chang D (2008) Seroma development following body contouring surgery for massive weight loss: patient risk factors and treatment strategies. Plast Reconstr Surg 122:280-288

30. Stewart K, Stewart D, Coghlan B et al (2006) Complications of 278 consecutive abdominoplasties. J Plast Reconstr Aesthet Surg 59:1152-1155 